\title{
Research Article \\ Real-Time Implementation of Islanded Microgrid for Remote Areas
}

\author{
Monika Jain, ${ }^{1}$ Sushma Gupta, ${ }^{1}$ Deepika Masand, ${ }^{2}$ Gayatri Agnihotri, ${ }^{1}$ and Shailendra Jain ${ }^{1}$ \\ ${ }^{1}$ Department of Electrical Engineering, Maulana Azad National Institute of Technology (MANIT), Bhopal 462003, India \\ ${ }^{2}$ Department of Electrical \& Electronics Engineering, Oriental Institute of Science \& Technology (OIST), Bhopal 462021, India
}

Correspondence should be addressed to Monika Jain; chahatfeb2035@yahoo.co.in

Received 9 November 2015; Revised 6 February 2016; Accepted 15 February 2016

Academic Editor: Qiaoling Tong

Copyright (C) 2016 Monika Jain et al. This is an open access article distributed under the Creative Commons Attribution License, which permits unrestricted use, distribution, and reproduction in any medium, provided the original work is properly cited.

\begin{abstract}
Islanding is a condition in which a microgrid or a portion of power grid, consisting of distributed generation (DG) sources, converter, and load, gets disconnected from the utility grid. Under this condition the DG sources in a microgrid must switch to a voltage control mode, in order to provide constant voltage to local loads. In grid connected mode, the microgrid works as current controller and injects power to the main grid, depending on the power generation and local load with suitable market policies. Providing constant voltage at a stable frequency with proper synchronization amongst each DG in a microgrid is a challenge. The complexity of such grid requires careful study and analysis before actual implementation. These challenges of microgrid are addressed using real time OPAL-RT simulation technology. Thus the paper describes an islanded microgrid with master slave controller for power balance, voltage/frequency regulation, and synchronization. Based on an advanced real-time platform named Real-Time Laboratory (RT-LAB), the impacts of the micro sources, load, and converters in an islanded microgrid is studied in this paper. The effectiveness of the proposed controller is analyzed through experimental results under balanced/unbalanced nonlinear loads condition.
\end{abstract}

\section{Introduction}

Regular depletion of conventional energy sources has led the society to think of other alternative resources which will continue to cater the increasing demand of energy. One such alternative is an accretion of small scale renewable resources to form a microgrid and supply to a regional area $[1,2]$. Microgrid can operate in two distinct modes: (1) grid connected and (2) islanded (autonomous) mode. In grid connected mode, the microgrid works as current controller and injects power to the main grid, depending on the power generation and local load with suitable market policies [3]. Microgrid can come in islanded/autonomous mode due to disturbances, such as a fault and its subsequent switching incidents, or due to preplanned switching events or due to unavailability of resources. In islanded mode, microgrid works as voltage controller and is responsible for voltage control as well as for power sharing and balancing. The role of power sharing features is to ensure that all modules share the load according to their rating and availability of power from their energy source. In islanded mode converters always require grid-forming (master) power converters; otherwise there is no voltage reference and no control to maintain the power balance. In the single master operation, one unit operates as a grid-forming converter. The other units operate as grid-following units. In the multimaster operation, more than one unit is grid-forming, possibly combined with gridfeeding converters. In this work one of the units (DG) is acting as master controller and other units are acting as a slave controller. The master DG operates as voltage controlled source and the rest of them as slave DGs which operate as current controller. The master controller works like gridforming power converters and the main aim is to regulate the voltage and frequency of the microgrid. The slave DGs work like grid-feeding power converters and are controlled as current source, allowing active and reactive power modulation depending on voltage and frequency measurements at their Point of Common Coupling (PCC). Therefore, this kind of converter cannot operate independently in island mode $[4,5]$. Since a microgrid comprises a number of 
micro sources, their synchronization with each other is an important task. When interconnecting the microgrid with the main grid, many authors have developed the synchronization algorithms [6-8] considering each micro source as a DC source. But in a microgrid maintaining constant voltage and frequency, each micro source is an important issue in addition to synchronization. This paper proposes a masterslave controller for synchronization/resynchronization of all the DGs, regulation of voltage/frequency, and effective power sharing among the micro sources. The islanded microgrid is formed by two DG units. Each unit consists of Self-Excited Induction Generator (SEIG) driven by ABB drive, controller, battery for storage, and load. The impact of the parallel operated DG units has to be carefully studied and analyzed before actual realization. This is achieved with the help of real-time simulation platform; the Real-Time Laboratory (RT-LAB) developed by OPAL-RT Technologies [9-11].

\section{System Configuration}

Microgrid architecture is shown in Figure 1, operating in islanded mode. Islanding is a situation where microgrid is disconnected from the main utility but remains energized and continues to supply local loads. Microgrid can be formed by numbers of micro sources connected together. This paper considers an islanded microgrid formed by two DG units. Each unit consists of SEIG based micro sources, controllers with storage system, and loads. The SEIGs are preferred in microgrid due to their robust construction, less maintenance, and so forth $[12,13]$.

The SEIG requires constant reactive power support for voltage build up, which is provided by conventional capacitor banks. The controller is used to regulate voltage/frequency and active/reactive power under varying load and fault conditions, thus maintaining the SEIG terminal voltage and frequency constant. When these SEIGs are connected to form a microgrid, an additional problem of phase angle mismatch also occurs. The control algorithm proposed in this paper effectively synchronizes the DGs in addition to power sharing and voltage/frequency regulation in a microgrid. The proposed controller is also effective when one micro source is shut down due to unavailability of resources or due to a fault in the line. The controller provides proper phase matching when the outage micro source is reconnected to the system. The system parameters used for experimental analysis are mentioned in appendix.

\section{Control Strategy for Proposed Controller}

A microgrid is said to be in islanded mode when it is disconnected from the main grid and it operates independently with micro sources and load. In the proposed work autonomous microgrid is formed by considering two units only.

Each unit consists of induction motor driven $\mathrm{ABB}$ drive, with star connected fixed capacitor bank, the conversion unit which performs the interface function between the DC link and the generated three-phase voltages of micro source, and LC filter that transports and distributes the energy to the load and three-phase nonlinear load. In the proposed configuration two such units are connected in parallel through line impedances; values are mentioned in appendix. Figure 2 shows the proposed schematic diagram for one unit with its firing scheme. When the microgrid is disconnected from main grid that is islanded condition, each micro source should operate in voltage control mode and provide a constant voltage to the local loads. In addition to this, synchronization of microgrid is also important due to unpredictable renewable energy resources and varying electrical loads.

In parallel operation of micro sources, phase angle, frequency, and voltage difference should be as close as possible. This is called synchronization. Thus in a microgrid system synchronizing conditions should be fulfilled by each generating unit in order to connect them in parallel with varying load $[6,7]$.

This is achieved by the proposed topology. This topology uses a DQ and Phase Lock Loop (PLL), a PI regulator, and an integrator. The synchronizing scheme using DQ algorithm is depicted in Figure 3. The $V_{q}$ is set to zero. This becomes the input of PI regulator and its output is an angle (theta, denoted by $\left.\theta_{\text {old }}\right)$. This $\theta_{\text {old }}$ is compared with the $\theta_{\text {new }}$ to generate the reference angle for all micro sources. This angle $\left(\theta_{\text {new }}\right)$ can be the angle between the grid and micro source; in the islanded mode of microgrid this angle is obtained from any reference (master) source and the rest is acting like slave source. Here plant one is considered as master plant and other two plants are considered as slave plant [7]. The $\theta_{\text {new }}$ is generated as follows.

Assume that the phase difference between the two micro sources voltages ( 1 and 2 ) is given by

$$
\theta=\angle V_{g 1}-\angle V_{g 2} \text {. }
$$

In order to obtain the information of $\theta$, two sets of voltage values are used:

$$
\begin{aligned}
& k=V_{g a 1} V_{g a 2}+V_{g b 1} V_{g b 2}+V_{g c 1} V_{g c 2}, \\
& g=V_{g a 1} V_{g b 3}+V_{g b 1} V_{g c 3}+V_{g c 1} V_{g a 3} .
\end{aligned}
$$

Using the variables $k$ and $g, \sin (\theta)$ can be found as

$$
\sin (\theta)_{\text {new }}=\frac{[4 / 3(\mathrm{~g})+2 / 3(\mathrm{k})]}{[\sqrt{3}]} .
$$

When this $(\theta)_{\text {new }}$ is compared with $\theta_{\text {old }}$, the final reference angle $\left(\theta_{\text {final }}\right)$ will be generated.

The synchronizing angle $\theta_{\text {final }}$ obtained is used to generate unit vector template as shown in Figure 4. The unit templates are obtained as

$$
\begin{aligned}
& U_{v a}=\sin \left(\theta_{\text {final }}\right), \\
& U_{v b}=\sin \left(\theta_{\text {final }}-\frac{2 \pi}{3}\right), \\
& U_{v c}=\sin \left(\theta_{\text {final }}+\frac{2 \pi}{3}\right) .
\end{aligned}
$$




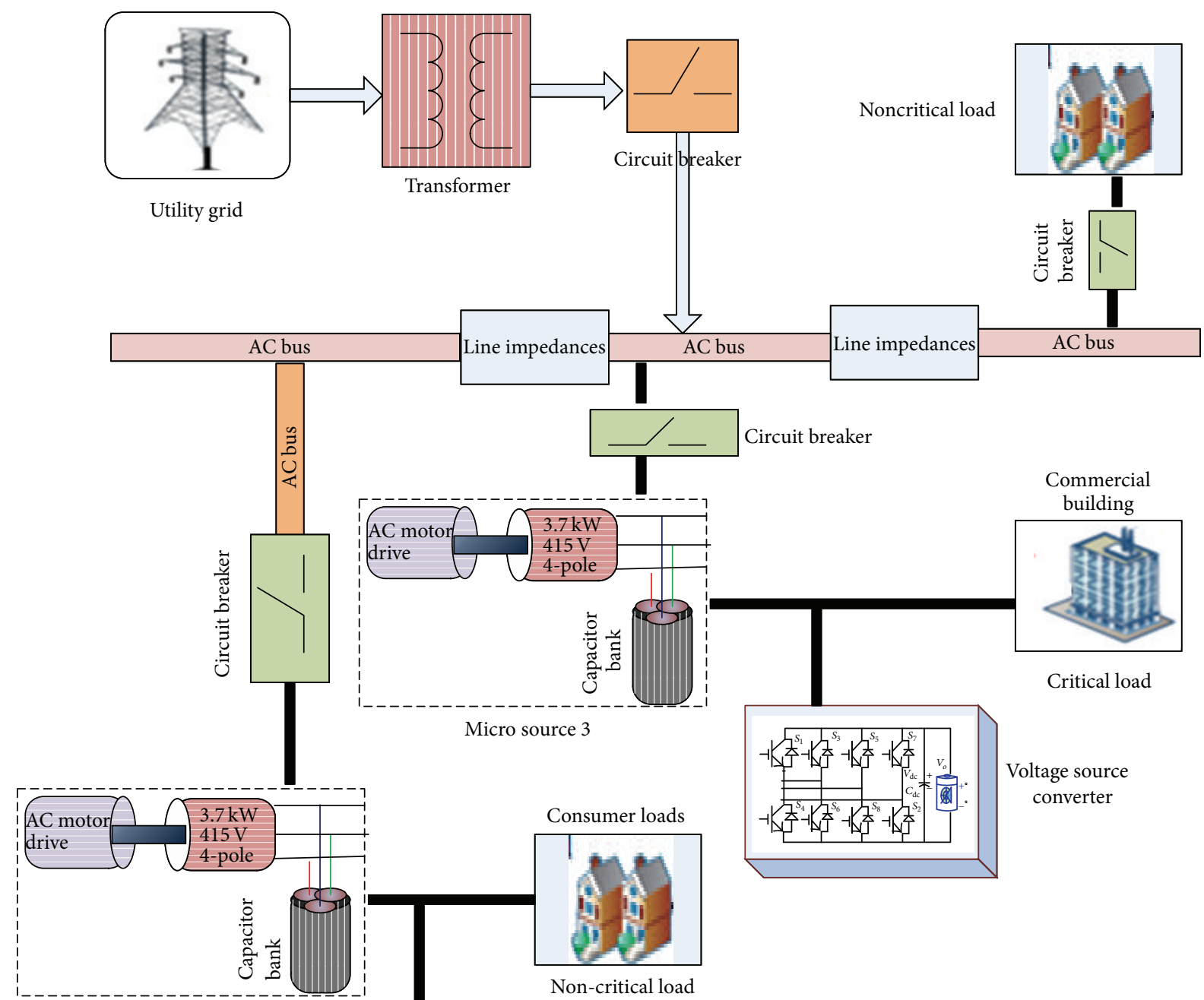

Micro source 1
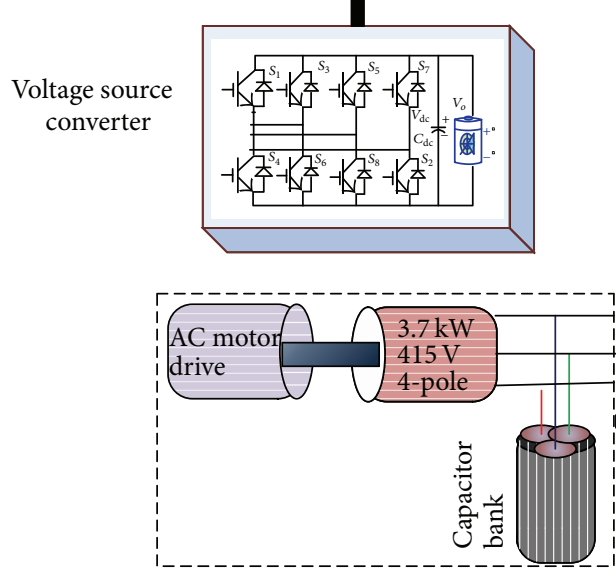

Micro source 2

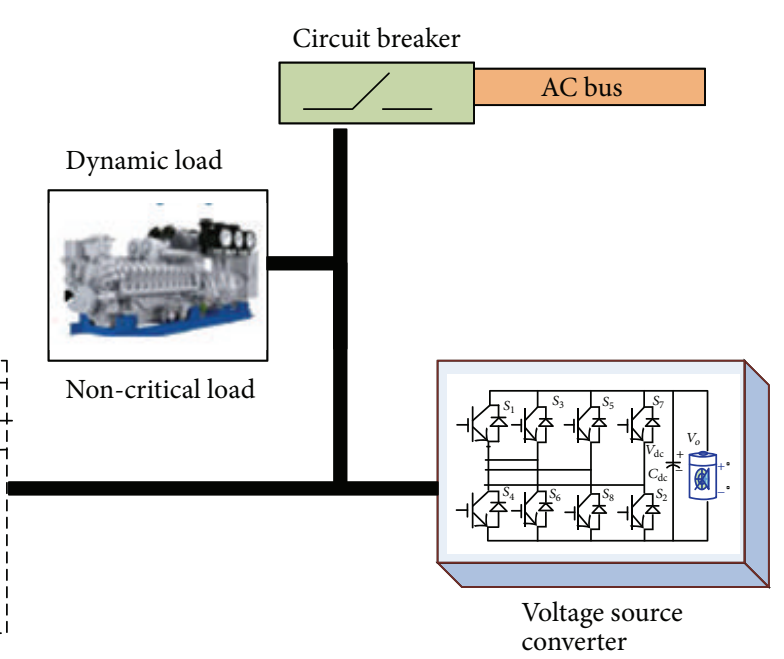

FIGURE 1: Microgrid architecture.

Figures 5 and 6 depict the block diagrams of the control algorithm employed for the proposed system. In this algorithm the master controller is based on frequency and voltage regulation. The slave controller is based on active/reactive power balance theory $[12,14,15]$.
The proposed microgrid in islanded mode comprises one master DG which behaves as an ideal voltage source and one slave DG which can be represented as ideal current source. Any voltage and frequency deviations are regulated by the master controller. Therefore voltage and frequency controller 


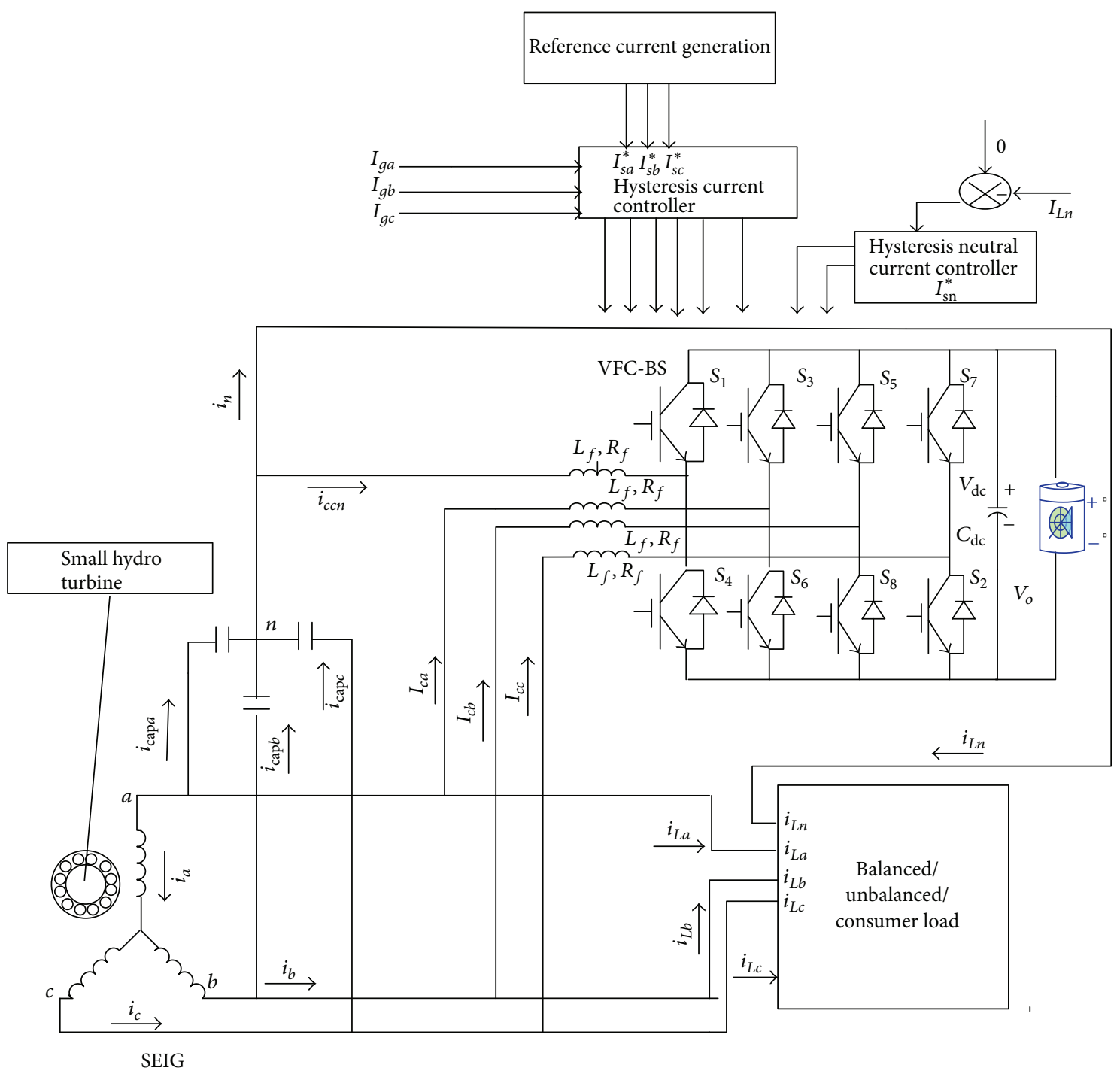

FIgURE 2: The illustrative diagram of plant "1" with its entire control unit.

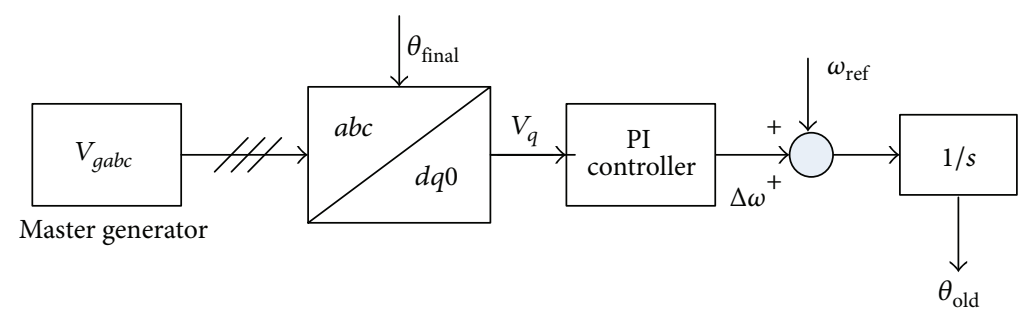

FIGURE 3: Synchronizing scheme using DQ algorithm.

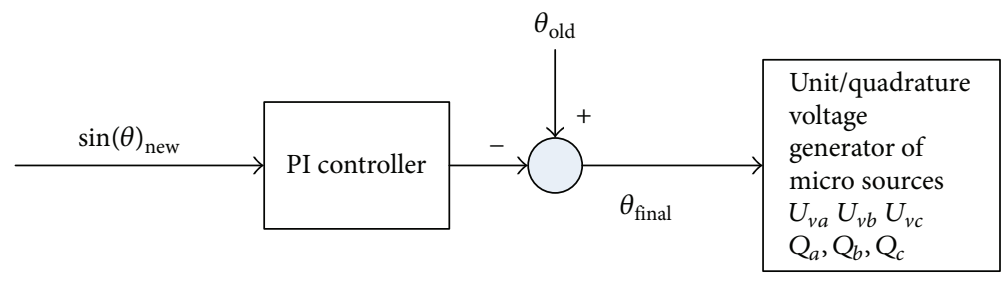

FIGURE 4: Generation of unit vector using synchronizing angle $\left(\theta_{\text {final }}\right)$. 


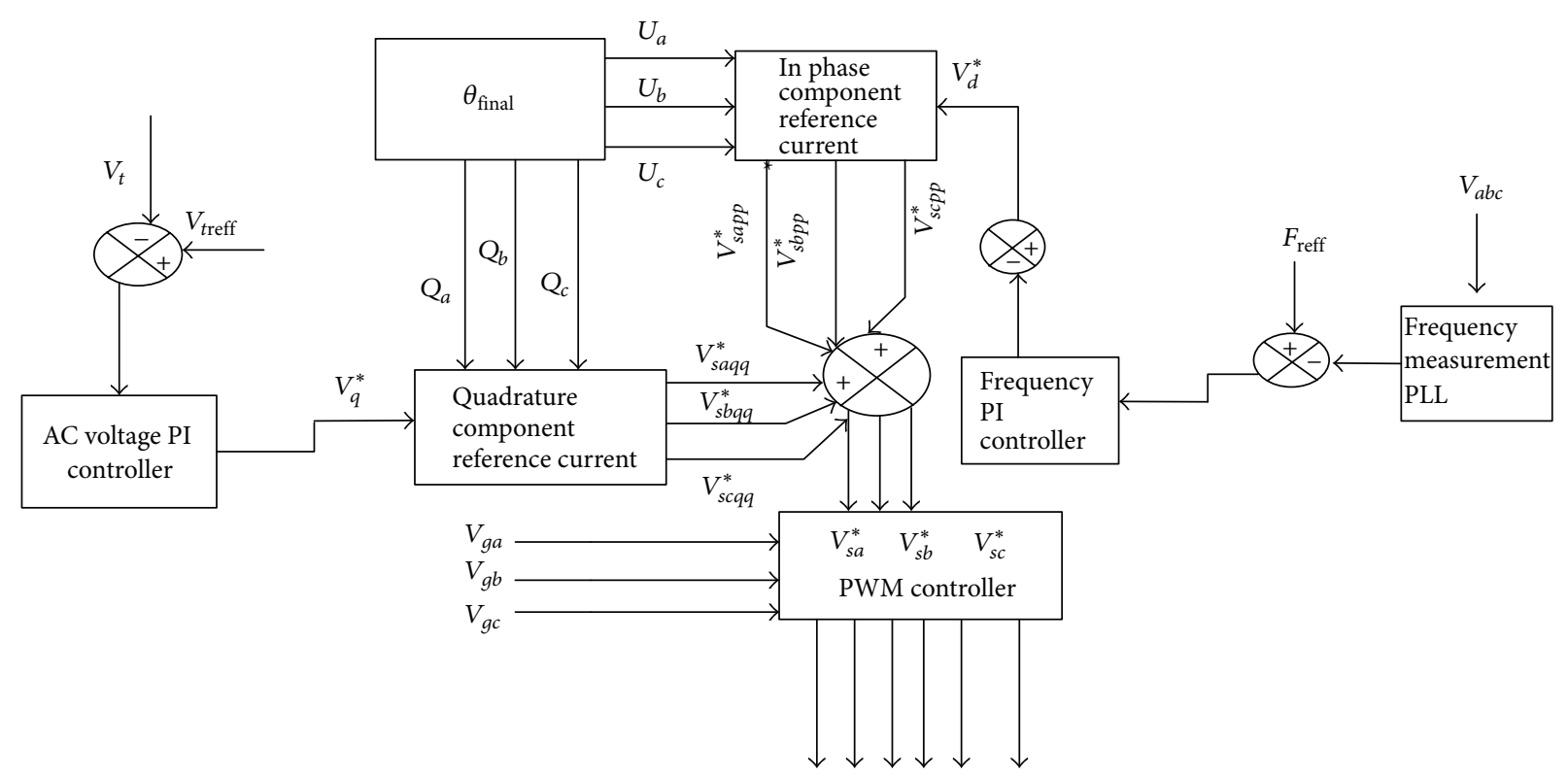

FIGURE 5: Control scheme for master controller for phase angle generation, voltage, and frequency regulation in microgrid.

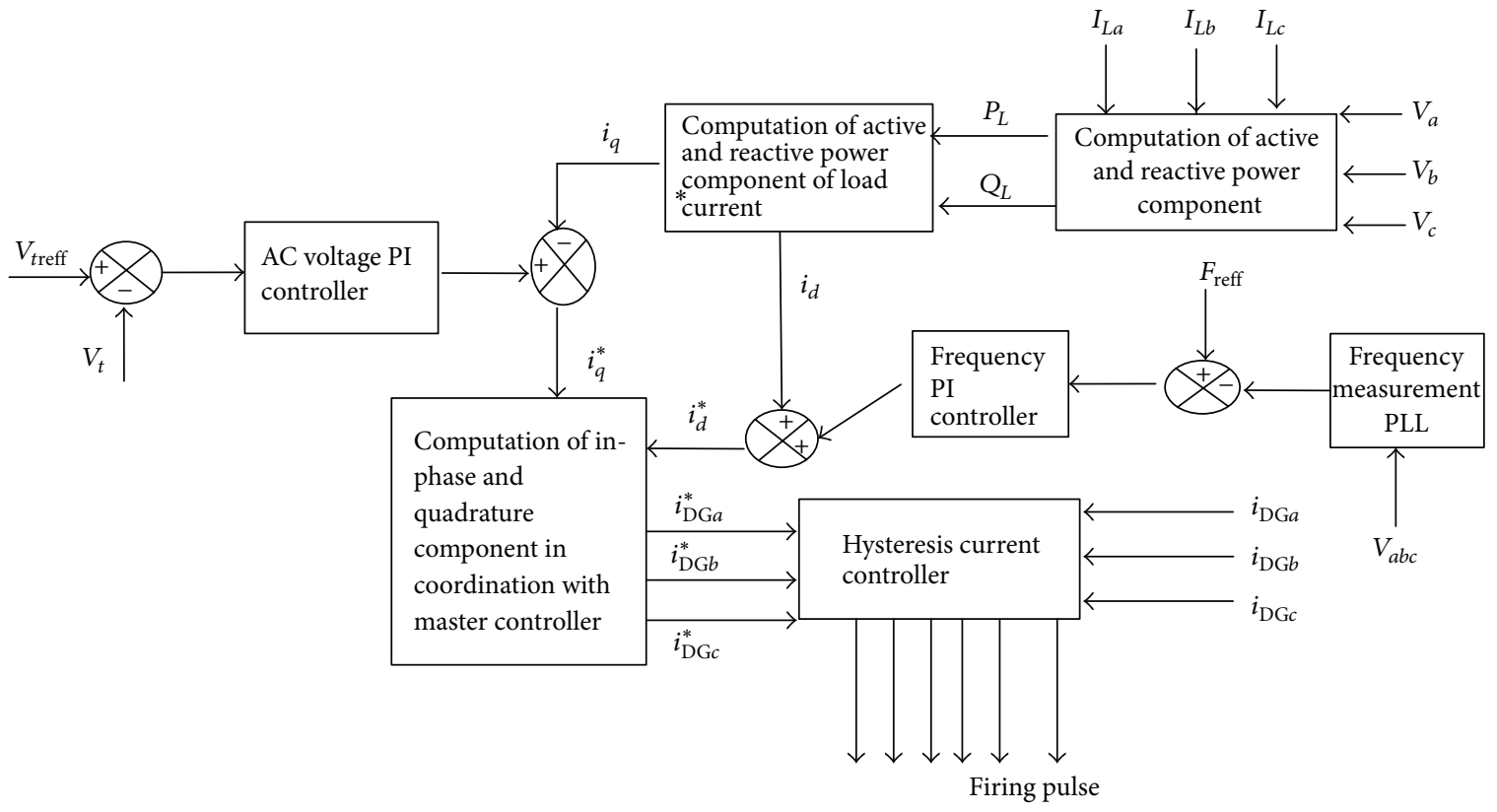

FIGURE 6: Control scheme for single slave controller in microgrid.

is utilized to compensate and adjust the system frequency and voltage within a stable range in addition to synchronization. The control scheme is based on the generation of reference source voltage $\left(V_{s a}^{*}, V_{s b}^{*}, V_{s c}^{*}\right)$. Reference source voltage has two components: (1) quadrature component $\left(V_{s a q q}^{*}, V_{s b q q}^{*}\right.$, $V_{s c q q}^{*}$ ) for controlling the magnitude of generator voltage and (2) in-phase component $\left(V_{s a p p}^{*}, V_{s b p p}^{*}, V_{s c p p}^{*}\right)$ for regulating the frequency of the system. The generation of direct and quadrature axis reference voltages is as per the diagram shown in Figure 5. These reference voltages $\left(V_{s a}^{*}, V_{s b}^{*}, V_{s c}^{*}\right)$ are compared with the sensed generator voltage $\left(V_{\mathrm{DG} a}, V_{\mathrm{DG} b}\right.$,
$V_{\mathrm{DGc}}$ ). The difference of these signals (error) is given to the PWM controllers which generate the firing pulses.

The master controller generates the reference angle for generation of in-phase and quadrature unit vector templates of the slave controller. The in-phase components of reference current are generated from the active power and the quadrature components of reference current are generated for the reactive power component. To estimate the active component of the reference source current as shown in Figure 6, the instantaneous active power of the load is calculated from micro source voltage and its load current. This power contains 


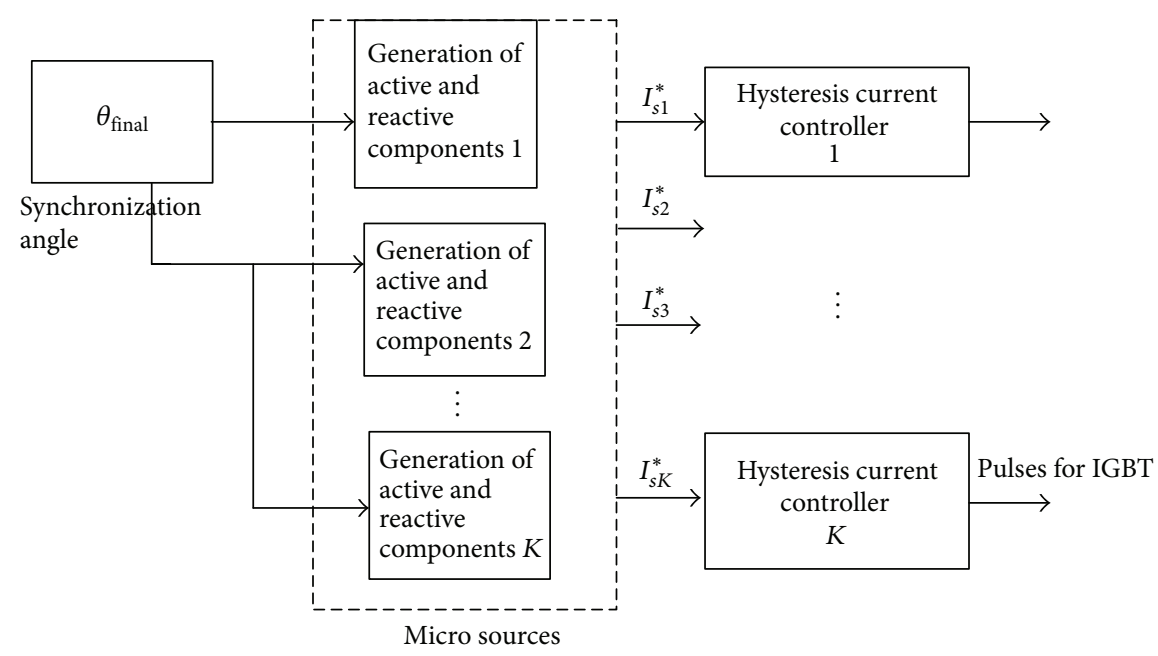

FIGURE 7: Centralized control scheme for microgrid.

an average or DC and AC or oscillating components. Thus, in order to extract the DC component of the load power, a low pass filter is used. The active load current is obtained by dividing the output of filter with the terminal voltage and denoted by $I_{d}$. The output of frequency PI controller is added with the DC component $\left(I_{d}\right)$ of the load current to generate the reference in-phase current $\left(I_{d}^{*}\right)$. This current when multiplied with the unit vector, generates the threephase reference in-phase current.

Similarly the reactive power component is calculated and is denoted by $I_{q}$. The output of terminal voltage PI controller is subtracted with the DC component $\left(I_{q}\right)$ of the load current to generate the reference quadrature current $\left(I_{q}^{*}\right)$. This current when multiplied with the quadrature vector, generates the reference three-phase quadrature current. The sum of these components yields the total reference current $\left(I_{s a}^{*}, I_{s b}^{*}, I_{s c}^{*}\right)$. These reference currents are then compared with the sensed generator currents $\left(I_{\mathrm{DG} a}, I_{\mathrm{DG} b}, I_{\mathrm{DG} c}\right)$. The difference between these signals (error) is given to the controller as shown in Figure 6. For neutral current compensation, sensed neutral current is compared with the reference current $\left(i_{s n}^{*}=0\right)$ and the difference is given to the controller. The hysteresis controller generates the pulses for the IGBTs in a 4-leg voltage source converter. Figure 7 shows the control algorithm for all slaves controller. The micro sources are represented by number $1,2,3, \ldots, K$ and the total capacity " $S$ " of the microgrid is the sum of total individual micro sources.

\section{Performance of Proposed Controller Using OPAL-RT}

In order to analyze the behavior of a microgrid before practical implementation, real-time digital simulation is essential and beneficial. Hence to validate the functionality of microgrid before the on-site implementation, it is not only beneficial but also necessary to test operation of microgrid in real-time conditions. The OPAL-RT-LAB simulator [9] enables the parallel simulation of power drives and electric
TABLE 1: Scaling parameters.

\begin{tabular}{lcc}
\hline Parameters & Actual value & Scaling value \\
\hline Generator voltage & $600 \mathrm{~V}\left(415 \mathrm{~V}_{\mathrm{rms}}\right)$ & $6 \mathrm{~V}$ \\
Generator current & $10 \mathrm{~A}$ & $10 \mathrm{~A}$ \\
Load current & $10 \mathrm{~A}$ & $10 \mathrm{~A}$ \\
Terminal voltage & $600 \mathrm{~V}$ & $6 \mathrm{~V}$ \\
Frequency & $50 \mathrm{~Hz}$ & $5 \mathrm{~Hz}$ \\
Load neutral current & $10 \mathrm{~A}$ & $10 \mathrm{~A}$ \\
Neutral current controller & $10 \mathrm{~A}$ & $10 \mathrm{~A}$ \\
\hline
\end{tabular}

circuits. Using standard Simulink models, RT-LAB builds computation and communication tasks necessary to make parallel simulation of electrical systems with standard PCs and communication links [9-11]. A discrete fixed step size of $20 \mu$ s is used to compute the proposed controller. In all the experiments, the measured variables available in controller block running on real-time digital simulator were scaled down as given in Table 1, before sending them to realtime digital simulator output ports for their display on a Digital Storage Oscilloscope (DSO). Furthermore, measured variables are scaled down when they reach the monitoring ports of the real-time simulator. Measured variables from monitoring ports of the real-time digital simulator were then directly displaced on the DSO. Therefore in order to determine actual value of a variable, DSO reading has to be multiplied by scaling parameter. After some modification the model can run in RT-LAB environment and the corresponding steady state and transient performance of a proposed controller for a microgrid with balanced and unbalanced nonlinear load is shown in Figure 8. To observe the performance of microgrid under OPAL-RT two SEIGs of the same rating driven by $\mathrm{ABB}$ drive are taken as micro sources and converter unit, and load is considered. The realtime results of the other micro sources are also the same as they are of the same rating. Figures 8 and 9 represent generator voltage $\left(V_{g}\right)$, generator current $\left(I_{g}\right)$, load current 


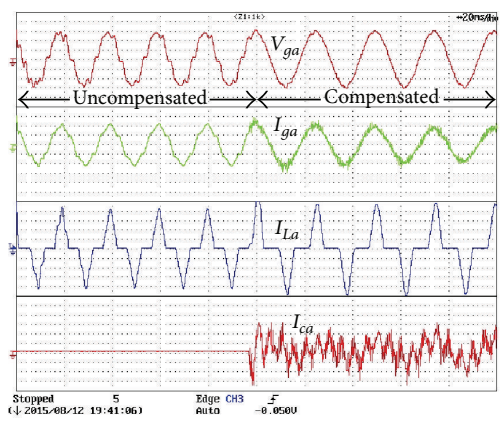

(a) $\mathrm{CH} 1: 6 \mathrm{~V}, \mathrm{CH} 2, \mathrm{CH} 3$, and $\mathrm{CH} 4: 10 \mathrm{~A}$

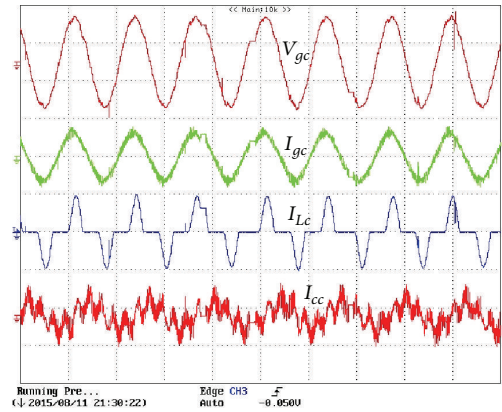

(d) $\mathrm{CH} 1: 6 \mathrm{~V}, \mathrm{CH} 2, \mathrm{CH} 3$, and $\mathrm{CH} 4: 10 \mathrm{~A}$

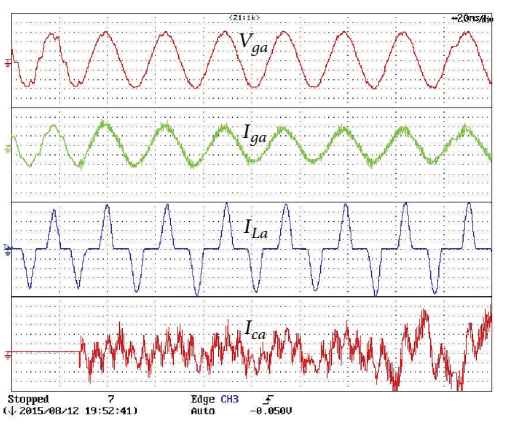

(b) $\mathrm{CH} 1: 6 \mathrm{~V}, \mathrm{CH} 2, \mathrm{CH} 3$, and $\mathrm{CH} 4: 10 \mathrm{~A}$

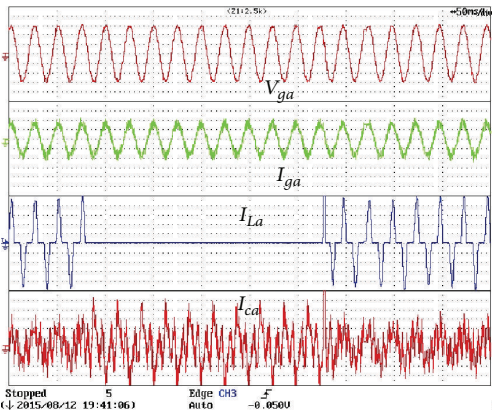

(e) $\mathrm{CH} 1: 6 \mathrm{~V}, \mathrm{CH} 2, \mathrm{CH} 3$, and $\mathrm{CH} 4: 10 \mathrm{~A}$

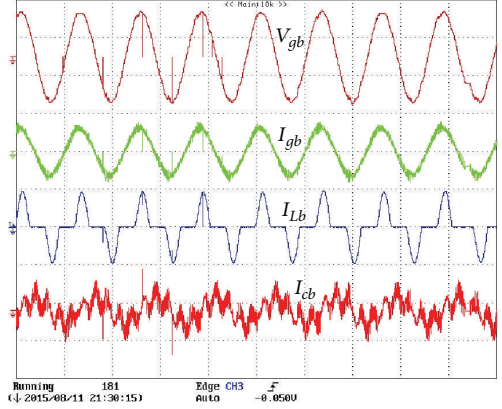

(c) $\mathrm{CH} 1: 6 \mathrm{~V}, \mathrm{CH} 2, \mathrm{CH} 3$, and $\mathrm{CH} 4: 10 \mathrm{~A}$

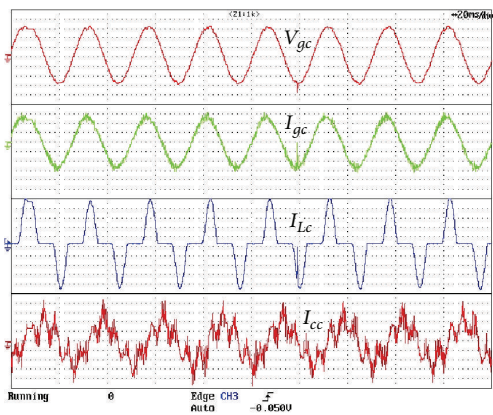

(f) $\mathrm{CH} 1: 6 \mathrm{~V}, \mathrm{CH} 2, \mathrm{CH} 3$, and $\mathrm{CH} 4: 10 \mathrm{~A}$

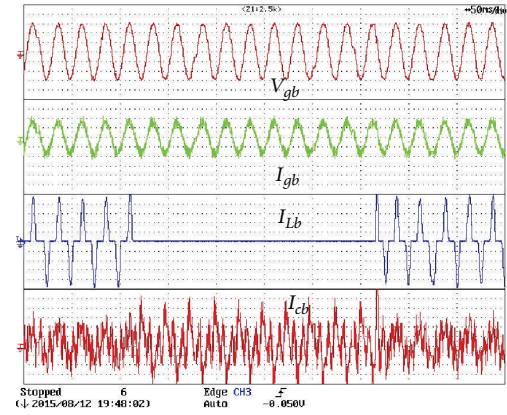

(g) $\mathrm{CH} 1: 6 \mathrm{~V}, \mathrm{CH} 2, \mathrm{CH} 3$, and $\mathrm{CH} 4: 10 \mathrm{~A}$

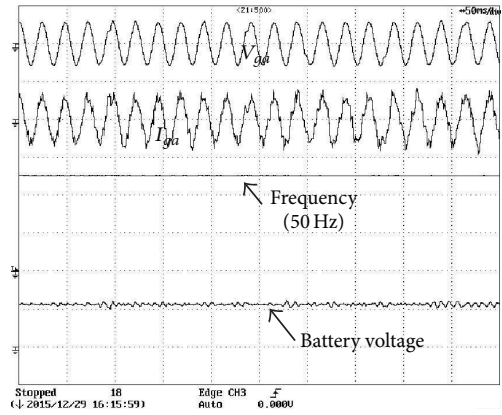

(h) $\mathrm{CH} 1: 6 \mathrm{~V}, \mathrm{CH} 2: 10 \mathrm{~A}, \mathrm{CH} 3: 50 \mathrm{~Hz}$, and CH4: $6 \mathrm{~V}$

FIGURE 8: Experimental result for the proposed system on DSO (a) with/without controller: (b)-(d) load is balanced and (e)-(g) load is unbalanced. (h) Battery voltage, frequency with generator voltage, and current.

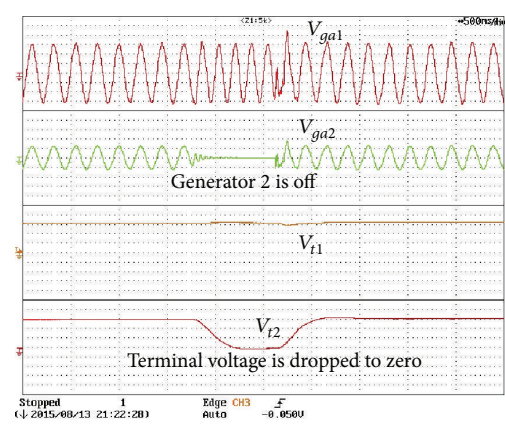

(a) $\mathrm{CH} 1$ and $\mathrm{CH} 2: 6 \mathrm{~V} ; \mathrm{CH} 3$ and $\mathrm{CH} 4: 6 \mathrm{~V}$

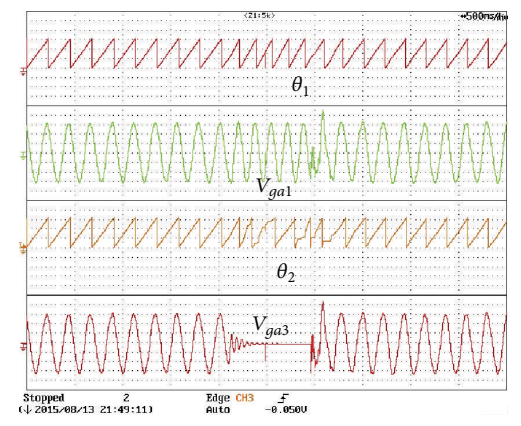

(b) $\mathrm{CH} 2$ and $\mathrm{CH} 4: 6 \mathrm{~V}$

FIGURE 9: Experimental result on DSO after resynchronization of micro source 2 after fault clearing. 
$\left(I_{L}\right)$, controller current $\left(I_{c}\right)$, load neutral current $\left(I_{L n}\right)$, and neutral current controller $\left(I_{L n c}\right)$. $V_{g a}$ represents the generator voltage of phase " $a$ " for both generators.

Figure $8(\mathrm{a})$ shows the effect of nonlinear load on the system without controller. As the controller is turned on after 5 cycles, the voltage and current become sinusoidal. Figures 8 (b) $-8(d)$ describe the steady state performance of compensated microgrid system with the application of nonlinear load. Figure 8(e) shows the unbalanced behavior of a three-phase nonlinear load for 11 cycles. Figures 8(f)8 (h) show the transient performance of microgrid system in all the three phases. The source voltage and current are purely sinusoidal even during the unbalance condition. In Figure 8(h) load neutral current and controller current are shown, which are opposite in nature, thus reducing the magnitude of neutral current and size of conductor. Figure 9(a) describes the generator voltage during and after the fault clearing. After the fault clearing both generator voltages must be synchronized to be operating in parallel and form the gird. During synchronization the phase angles must be the same. As shown in Figure 9(a), as the fault arises in generator " 2 " for 5 cycles, it thus disconnected from the grid. During this period phase angle of generator " 2 " gets distorted as shown in Figure 9(b). After fault clearing both generators get resynchronized after two cycles because of effective operation of the proposed controller.

\section{Conclusion}

The highest potential for microgrid is in remote regions, where grid connection is not possible. The proposed master/slave controller in the microgrid has been successfully demonstrated through OPAL-RT environment for nonlinear loads during transient and steady state conditions. The master controller regulates the voltage and frequency of the microgrid whereas slave controller works in indirect current control mode, thus regulating the active and reactive power. The controller works satisfactorily for sharing of loads during load perturbations and failure of one micro source in microgrid due to fault or unavailability of renewable resources and avoids critical load curtailment. The proposed scheme in autonomous mode ensures that the micro source (slave unit) can be effectively synchronized/resynchronized to a master micro source maintaining synchronizing criteria. The experimental results prove the performance of the controller under different transient and steady state conditions.

\section{Appendix}

Micro source 1, 2: $3.7 \mathrm{~kW}, 415 \mathrm{~V}, 50 \mathrm{~Hz}, 4$ pole.

LCL filter: $3.5 \mathrm{mH}, 20 \mu \mathrm{F}, 0.5 \mathrm{mH}$.

Line impedance: 0.0134 ' $\Omega, 0.02 \mathrm{mH}$.

Nonlinear load (each): $1.23 \mathrm{~kW}, 100 \mu \mathrm{F}, 8 \mathrm{mH}$ at DC end of single phase diode rectifier.

Passive filter $(R, C): 2^{\prime} \Omega, 15 \mu \mathrm{F}$.

PI parameters: $f_{\mathrm{pc}}=1, f_{\mathrm{ic}}=5, V_{\mathrm{pc}}=0.01, V_{\mathrm{ic}}=$ 0.0025 .

Converter rating (each micro source): 1200 V, 50 A.

\section{Competing Interests}

The authors declare that they have no competing interests.

\section{References}

[1] H. A. Gabbar and A. A. Abdelsalam, "Microgrid energy management in grid-connected and islanding modes based on SVC," Energy Conversion and Management, vol. 86, pp. 964-972, 2014.

[2] F. Katiraei, M. R. Iravani, and P. W. Lehn, "Micro-grid autonomous operation during and subsequent to islanding process," IEEE Transactions on Power Delivery, vol. 20, no. 1, pp. 248-257, 2005.

[3] N. W. A. Lidula and A. D. Rajapakse, "Microgrids research: a review of experimental microgrids and test systems," Renewable and Sustainable Energy Reviews, vol. 15, no. 1, pp. 186-202, 2011.

[4] T. L. Vandoorn, J. D. M. De Kooning, B. Meersman, and L. Vandevelde, "Review of primary control strategies for islanded microgrids with power-electronic interfaces," Renewable and Sustainable Energy Reviews, vol. 19, pp. 613-628, 2013.

[5] P. Basak, S. Chowdhury, S. HalderneeDey, and S. P. Chowdhury, "A literature review on integration of distributed energy resources in the perspective of control, protection and stability of microgrid," Renewable and Sustainable Energy Reviews, vol. 16, no. 8, pp. 5545-5556, 2012.

[6] C. Cho, J.-H. Jeon, J.-Y. Kim, S. Kwon, K. Park, and S. Kim, "Active synchronizing control of a microgrid," IEEE Transactions on Power Electronics, vol. 26, no. 12, pp. 3707-3719, 2011.

[7] I. J. Balaguer, Q. Lei, S. Yang, U. Supatti, and F. Z. Peng, "Control for grid-connected and intentional islanding operations of distributed power generation," IEEE Transactions on Industrial Electronics, vol. 58, no. 1, pp. 147-157, 2011.

[8] Y. W. Li and C.-N. Kao, "An accurate power control strategy for power-electronics-interfaced distributed generation units operating in a low-voltage multibus microgrid," IEEE Transactions on Power Electronics, vol. 24, no. 12, pp. 2977-2988, 2009.

[9] C. Dufour and J. Bélanger, "On the use of real-time simulation technology in smart grid research and development," IEEE Transactions on Industry Applications, vol. 50, no. 6, pp. 39633970, 2014

[10] W. Qiao, G. K. Venayagamoorthy, and R. G. Harley, "Real-time implementation of a STATCOM on a wind farm equipped with doubly fed induction generators," IEEE Transactions on Industry Applications, vol. 45, no. 1, pp. 98-107, 2009.

[11] V. Jalili-Marandi, P. Lok-Fu, and V. Dinavahi, "Real-time simulation of grid-connected wind farms using physical aggregation," IEEE Transactions on Industrial Electronics, vol. 57, no. 9, pp. 3010-3021, 2010.

[12] G. K. Kasal and B. Singh, "Voltage and frequency controllers for an asynchronous generator-based isolated wind energy conversion system," IEEE Transactions on Energy Conversion, vol. 26, no. 2, pp. 402-416, 2011.

[13] B. Singh, S. S. Murthy, and S. Gupta, "STATCOM-based voltage regulator for self-excited induction generator feeding nonlinear loads," IEEE Transactions on Industrial Electronics, vol. 53, no. 5, pp. 1437-1452, 2006.

[14] B. Singh and S. Sharma, "Power balance theory based voltage and frequency control for IAG in wind power generation," in Proceedings of the 2nd International Conference on Emerging 
Trends in Engineering and Technology (ICETET '09), pp. 40-45, IEEE, Nagpur, India, December 2009.

[15] V. Verma and G. G. Talpur, "Decentralized Master-Slave operation of microgrid using current controlled distributed generation sources," in Proceedings of the IEEE International Conference on Power Electronics, Drives and Energy Systems (PEDES '12), pp. 1-6, Bengaluru, India, December 2012. 


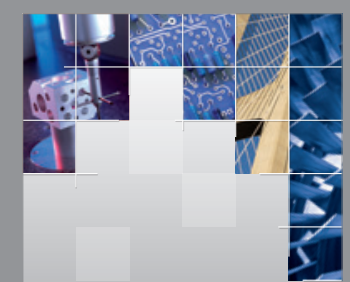

\section{Enfincering}
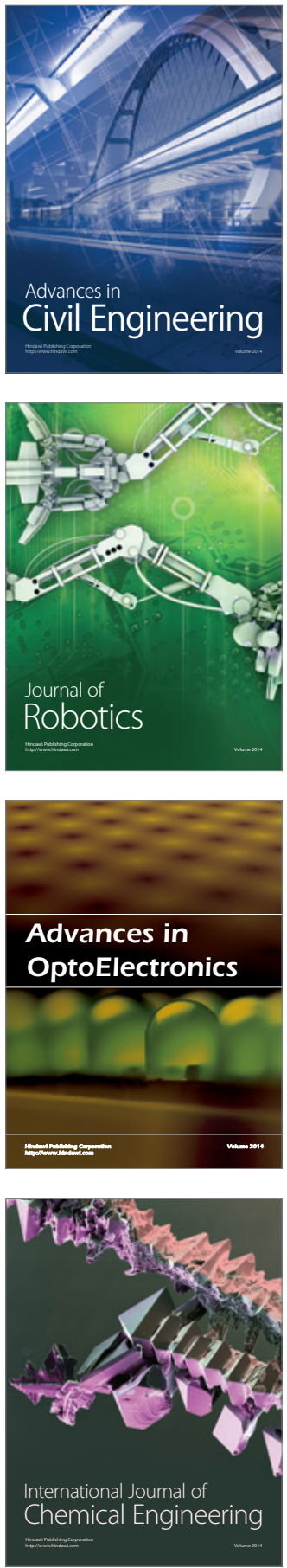

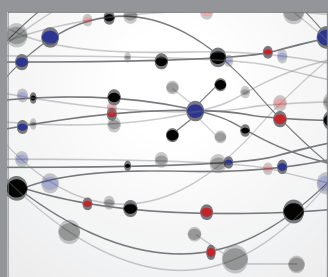

The Scientific World Journal

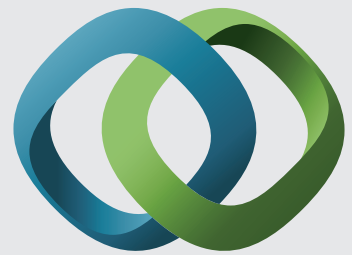

\section{Hindawi}

Submit your manuscripts at

http://www.hindawi.com
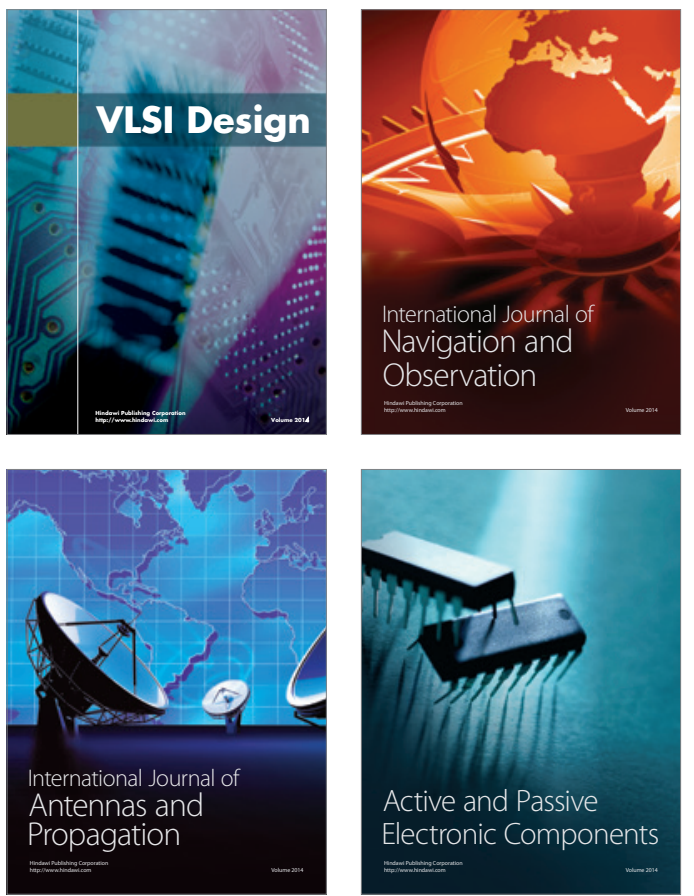
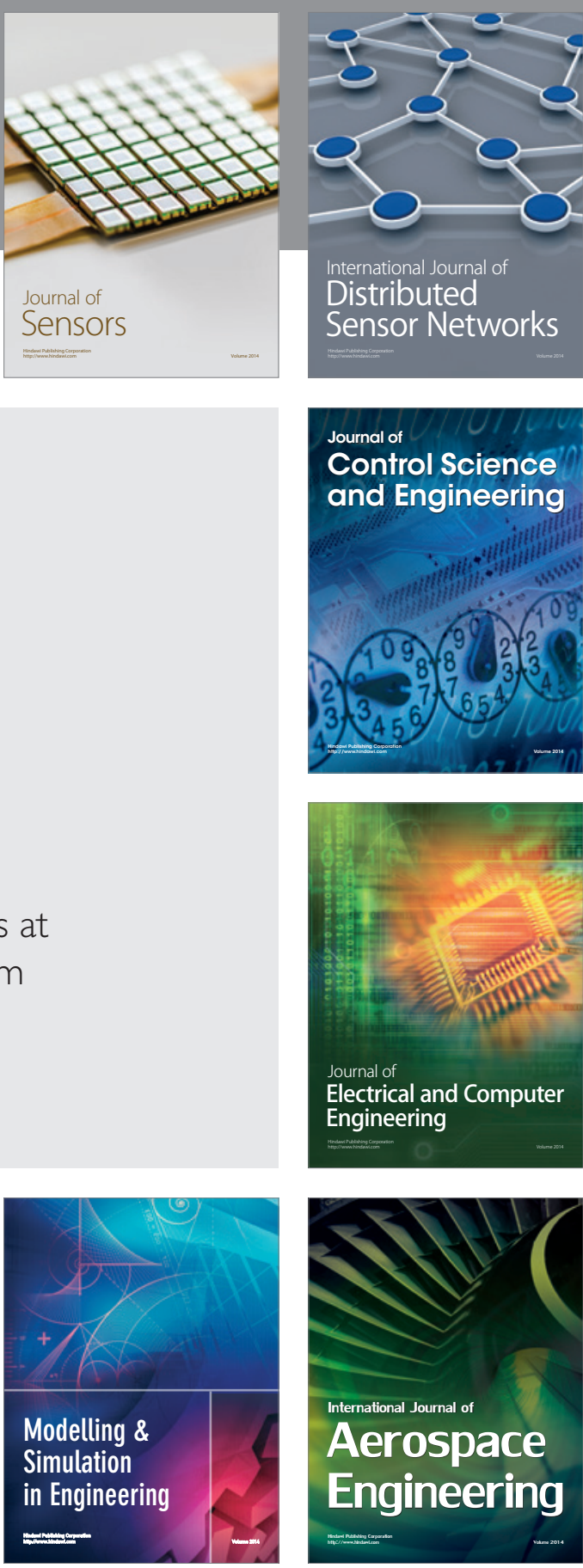

International Journal of

Distributed

Sensor Networks

Journal of

Control Science

and Engineering
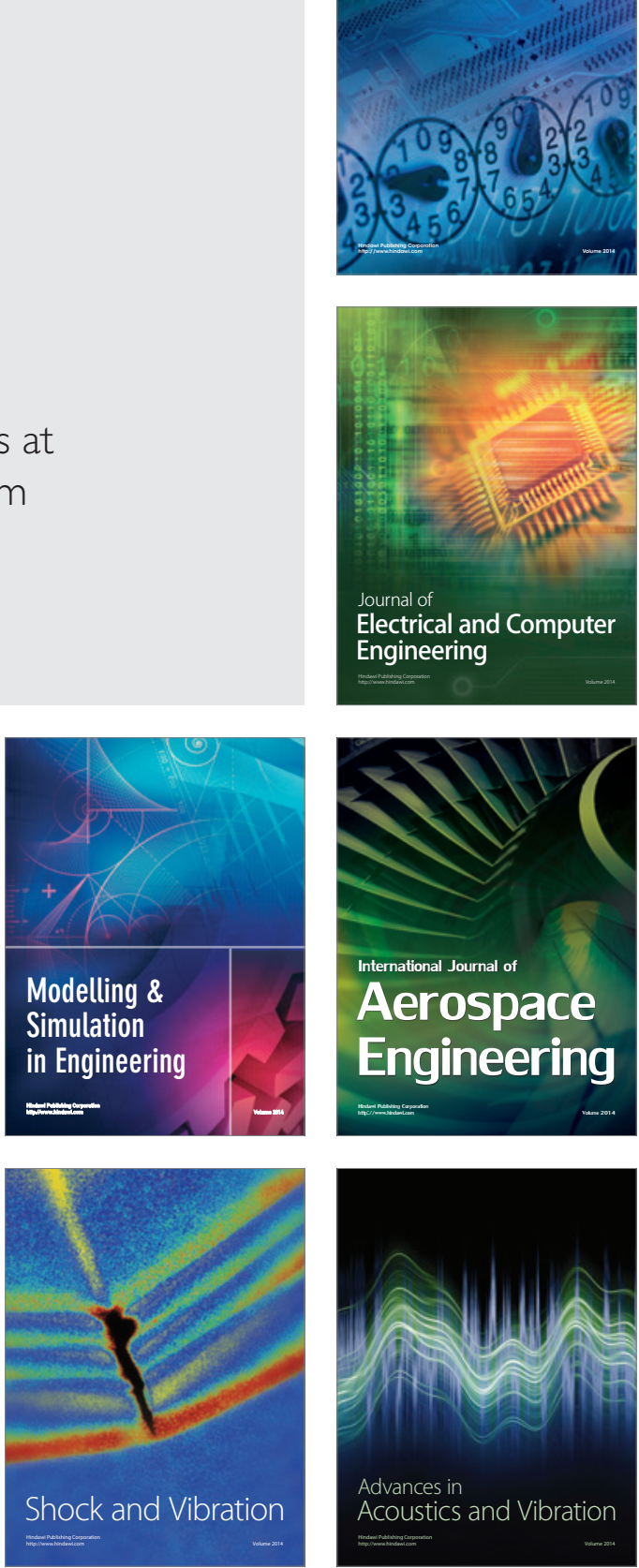